\title{
A disposable biosensor based on immobilization of laccase with silica spheres on the MWCNTs- doped screen-printed electrode
}

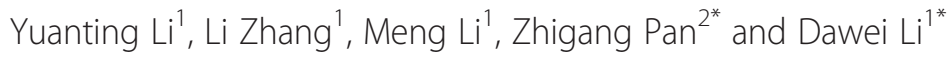

\begin{abstract}
Background: Biosensors have attracted increasing attention as reliable analytical instruments in in situ monitoring of public health and environmental pollution. For enzyme-based biosensors, the stabilization of enzymatic activity on the biological recognition element is of great importance. It is generally acknowledged that an effective immobilization technique is a key step to achieve the construction quality of biosensors.

Results: A novel disposable biosensor was constructed by immobilizing laccase (Lac) with silica spheres on the surface of multi-walled carbon nanotubes (MWCNTs)-doped screen-printed electrode (SPE). Then, it was characterized in morphology and electrochemical properties by scanning electron microscopy (SEM) and cyclic voltammetry (CV). The characterization results indicated that a high loading of Lac and a good electrocatalytic activity could be obtained, attributing to the porous structure, large specific area and good biocompatibility of silica spheres and MWCNTs. Furthermore, the electrochemical sensing properties of the constructed biosensor were investigated by choosing dopamine (DA) as the typical model of phenolic compounds. It was shown that the biosensor displays a good linearity in the range from 1.3 to $85.5 \mu \mathrm{M}$ with a detection limit of $0.42 \mu \mathrm{M}(\mathrm{S} / \mathrm{N}=3)$, and the Michaelis-Menten constant $\left(\mathrm{K}_{\mathrm{m}}^{\mathrm{app}}\right)$ was calculated to be $3.78 \mu \mathrm{M}$.

Conclusion: The immobilization of Lac was successfully achieved with silica spheres to construct a disposable biosensor on the MWCNTs-doped SPE (MWCNTS/SPE). This biosensor could determine DA based on a non-oxidative mechanism in a rapid, selective and sensitive way. Besides, the developed biosensor could retain high enzymatic activity and possess good stability without cross-linking reagents. The proposed immobilization approach and the constructed biosensor offer a great potential for the fabrication of the enzyme-based biosensors and the analysis of phenolic compounds.
\end{abstract}

\section{Background}

Laccase (Lac) has been widely used to construct electrochemical biosensors for phenolic and their derivatives, because it can catalyze the oxidation of phenolic compounds accompanied by the reduction of oxygen $[1,2]$. The high stability and enzymatic activity of the bioelectrochemical interfaces play a crucial role in the construction of Lac-based biosensors. The immobilization of enzymes on solid supports is one of the effective

\footnotetext{
* Correspondence: zhigang_pan@163.com; daweili@ecust.edu.cn 'Key Laboratory for Advanced Materials \& Department of Chemistry, School of Chemistry and Molecular Engineering, East China University of Science and Technology, 130 Meilong Road, Shanghai, P R China

${ }^{2}$ Zhongshan Hospital Fudan University, 180 Fenglin Road, Shanghai, P R China
}

strategies, which allows the recovering and reusing of enzyme for several reaction cycles $[3,4]$.

There is of intense interest in the construction of Lacbased biosensors using nanomaterials, due to their unique and particular properties [5]. Silica materials, which can accommodate different dimensions of enzyme without affecting their biological activity, could be considered as suitable hosts for enzyme immobilization $[6,7]$. For example, functionalized SBA-15 mesoporous silica was applied to immobilize Lac for the oxidation of a mixture of four phenolic compounds [8]. In another work, Lac was encapsulated into thin silicate film deposited on the Au electrode [9]. Moreover, magnetic mesoporous silica spheres were prepared to immobilize Lac as a promising support [10].
() ChemistryCentral 
Multi-walled carbon nanotubes (MWCNTs), with high surface area and excellent biocompatibility, are also a promising candidate as the matrix material to incorporate enzyme and construct enzyme-based biosensors [11,12]. Importantly, because of the low overvoltage and rapid electrode kinetics, MWCNTs have the ability to facilitate electron transfer of enzyme with the electrode [13]. Therefore, MWCNTs have been employed as the supporting materials of Lac, such as the matrix based on MWCNTs-chitosan composite film [2], polyazetidine prepolymer-MWCNTs integrated system [14], and copper nanoparticles/chitosan/carboxylated MWCNT/polyaniline composite [15]. Recently, researchers are committed to develop MWCNTs/silica nanocomposite as the immobilization materials of Lac, because they possess excellent properties of low toxicity and good electrocatalytic activity, and could provide a stabilizing microenvironment for Lac [16-18].

Screen-printed electrode (SPE) is a kind of planar sensor device with various substrates that are coated with layers of electroconductive and insulating inks at controlled thickness [19]. Several works related to the biosensors construction have been reported based on the immobilization of Lac on the SPEs, which could be incorporated in portable systems as an alternative detection method for the direct in-situ analysis [20-22]. It is notable that the most common way to construct electrochemical interfaces is to drop conductive substrates onto the electrode surfaces $[23,24]$. However, it is difficult to produce thin $(<1 \mathrm{~mm})$ layers and control the consistency of detection [25]. While printing technology provides a convenient route to produce electrochemical sensors with consistent chemical performances based on the modification of functional conductive materials, such as conducting polymers [19], ionic liquid [25] and enzyme [26,27]-doped conductive materials.

Herein, our goal is to construct a disposable electrochemical biosensor by immobilizing Lac on the MWCNTs-doped SPE using silica spheres as immobilization matrix (Lac/Si/MWCNTs/SPE) without cross-linking reagents. The morphology and the electrochemical properties of the constructed biosensor were characterized. Moreover, its electrochemical sensing properties were evaluated by selective measurements of dopamine (DA). Figure 1 depicts the procedures used for constructing the disposable biosensor and the mechanism for the determination of DA.

\section{Experimental}

\section{Reagents and apparatus}

Laccase from Trametes versicolor (EC 1.10.3.2, $21.8 \mathrm{U} \mathrm{mg}^{-1}$ ), dopamine (DA), ascorbic acid (AA) and tetraethyl orthosilicate (TEOS) were purchased from SigmaAldrich (St. Louis, MO, USA). All other reagents were of analytical reagent grade purity and all solutions were prepared using deionized water obtained with a Mili-Q system (Millipore Co., Bedford, MA, USA). MWCNTs were supplied by Shenzhen Nanotech Port Co. Ltd. (Shenzhen, China) with a typical diameter of $10-30 \mathrm{~nm}$ and length of 5-15 $\mu \mathrm{m}$, and their purity was $95-98 \%$. Besides, silver paste, carbon paste, silver/ silver chloride paste (Camnano Technology Ltd., Xuzhou, China), and insulating paste (Jujo Chemical Co., Ltd., Japan) were used to fabricate SPEs.

Scanning electron microscopy (SEM) results were obtained by using a Zeiss utra 55 field-emission SEM instrument (Zeiss, Germany). All the electrochemical measurements were performed with a CHI-1211A portable electrochemical workstation (Chenhua Instruments Co. Ltd., Shanghai, China). The measurements were performed at room temperature $\left(\sim 15^{\circ} \mathrm{C}\right)$.

\section{Fabrication of MWCNTS/SPE}

As the base electrodes for the printing process, SPEs with a standard three-electrode system and a $3.1 \mathrm{~mm}^{2}$ working area for each were fabricated according to the process described by our previous work $[28,29]$ with an AT-25P screen-printing machine (ATMA CHAMPENT. Corp., China). Compared to our previous publications, the working electrodes were printed using different mass proportions of MWCNT/carbon paste, drying at $100^{\circ} \mathrm{C}$. The prepared MWCNTs/SPEs were then stored at $4^{\circ} \mathrm{C}$ until required.

\section{Construction of the disposable biosensor}

Silica spheres were synthesized according to the Stöber's method [30]. Typically, a solution of $5 \mathrm{~mL}$ of $33 \%$ ammonia solution was mixed with $50 \mathrm{~mL}$ of dry ethanol. After $3.14 \mathrm{~mL}$ of TEOS and $1.8 \mathrm{~g}$ of Milli-Q water was added in sequence, the solution was stirred to hydrolyze TEOS. After $12 \mathrm{~h}$ of stirring, a colloidal solution of silica spheres about $100 \mathrm{~nm}$ in diameter were obtained.

Before modification, the bare SPEs were pretreated in $\mathrm{pH} 7.0$ potassium phosphate buffer solution (PBS) by applying an anodic potential of $2.00 \mathrm{~V}$ for $300 \mathrm{~s}$. The synthesized silica spheres colloidal suspension was mixed with Lac $\left(10.0 \mathrm{mg} \mathrm{mL} \mathrm{m}^{-1}\right.$, prepared in $0.10 \mathrm{M} \mathrm{pH}$ 5.0 PBS) stock solution thoroughly in a volume ratio $2: 3$ for 24 hours. Then, $2.5 \mu \mathrm{L}$ mixed solution of silica-Lac was coated onto the surface of the MWCNTs/SPE to form $\mathrm{Lac} / \mathrm{Si} / \mathrm{MWCNTs} / \mathrm{SPE}$ as the disposable biosensor. After the solvent evaporated, the constructed biosensor was washed with deionized water to remove excess Lac. For comparison, Lac modified SPE (Lac/SPE), Lac modified MWCNTs/SPE (Lac/MWCNTs/SPE), and silica spheres modified MWCNTs/SPE (Si/MWCNTs/SPE) were fabricated with the similar steps. All of the modified electrodes were stored at $4^{\circ} \mathrm{C}$. 


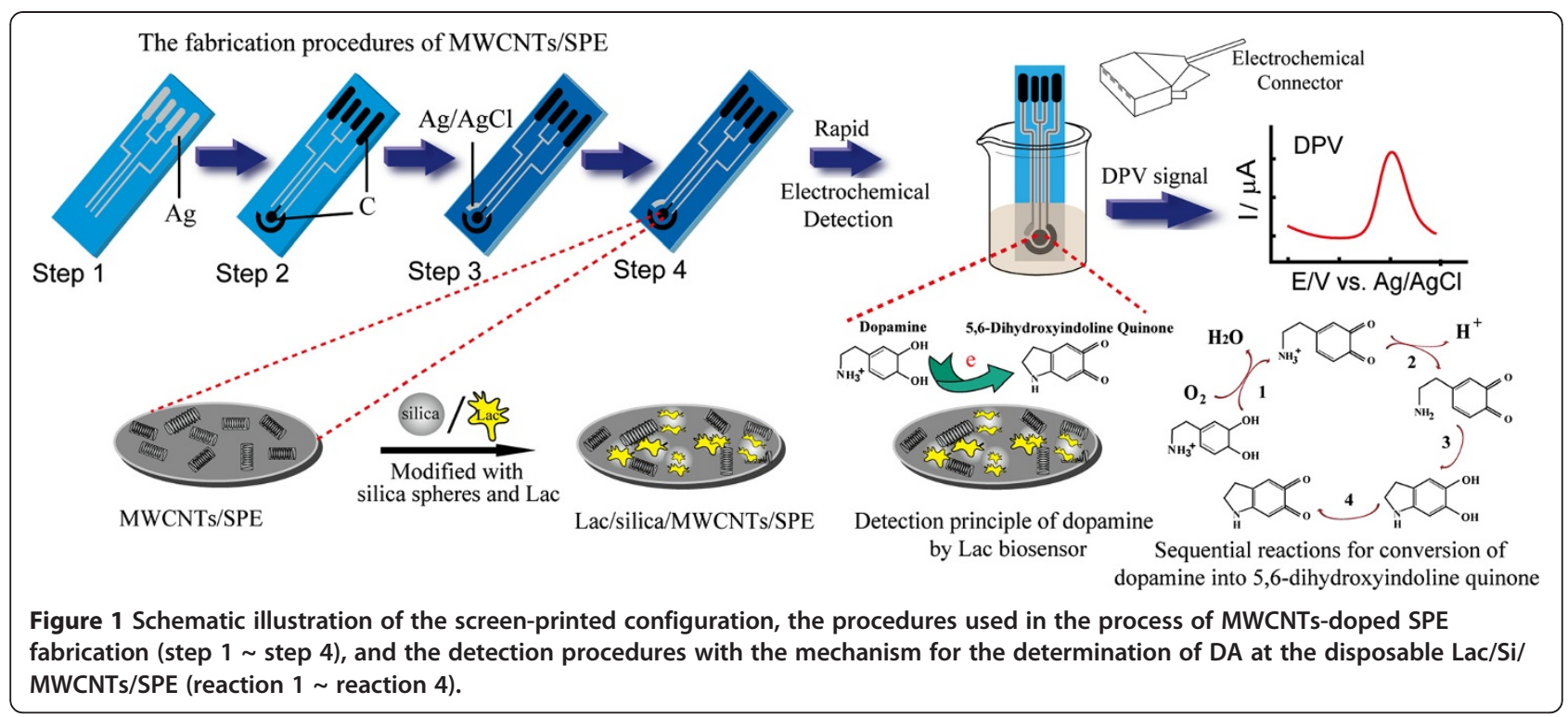

\section{Results and discussion}

Morphology characterization of the disposable biosensor The typical SEM images of the disposable biosensor at different preparation stages are displayed in Figure 2. It can be seen that the surface of the bare SPE is covered by a layer of carbon particles (Figure 2A). On the contrary, on the MWCNTs/SPE, twisted MWCNTs distribute among the carbon particles to form a threedimensional structure (Figure 2B). While, some of them are flat and embedded into the carbon particles, which may be due to the pressure during the screening process. After casting the silica solution loaded with Lac onto the MWCNTs/SPE, silica spheres can be found embedding into the Lac and connecting with each other
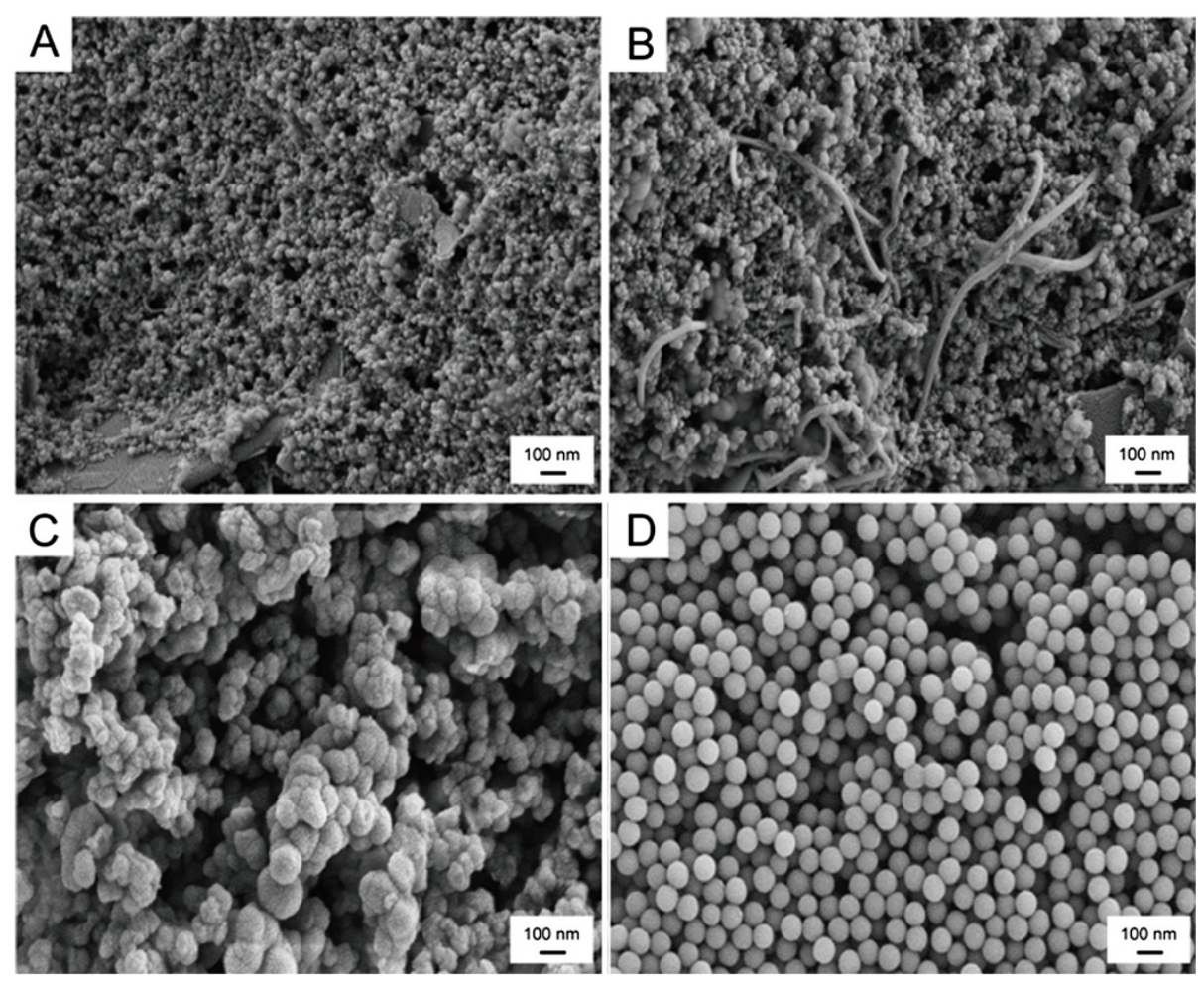

Figure 2 SEM images of (A) bare SPE, (B) MWCNTs/SPE, (C) Lac/Si/MWCNTs/SPE, and (D) silica spheres. 
(Figure 2C), which presented that Lac has been immobilized onto silica spheres successfully. For comparison, the SEM image of silica spheres is presented in Figure 2D.

\section{Electrochemical properties of the disposable biosensor}

The electrochemical sensing properties of the disposable biosensor were investigated by choosing DA as the typical model of phenolic compounds. In Figure 3, the electrocatalytic properties of the Lac/Si/MWCNTs/ SPE (Figure 3A), Lac/SPE (Figure 3B), Lac/MWCNTs/ SPE (Figure 3C), and Si/MWCNTs/SPE (Figure 3D) for DA were compared by performing cyclic voltammetry (CV) experiments in PBS solution ( $\mathrm{pH}$ 5.0). As we expected, no catalytic current responses are shown in the absence of DA (black curves in Figure 3A, B and C). In contrast, upon the presence of DA in solution, a pair of well-defined redox peaks is obtained (red curves in Figure $3 \mathrm{~B}$ and $\mathrm{C}$, and blue curve in Figure 3D). However, the voltammetric feature of the $\mathrm{Lac} / \mathrm{Si} / \mathrm{MWCNTs} / \mathrm{SPE}$ (red curve in Figure 3A) differs significantly, because a cathodic peak at around $-0.158 \mathrm{~V}$ vs. $\mathrm{Ag} / \mathrm{AgCl}$ appears. The height of this cathodic peak is sensitive to the change of the DA concentration in PBS (not shown here). The possible reason is essentially based on the demonstrated non- oxidative electrochemical approach [31] by taking advantage of the chemical properties of DA and the catalytic activity of Lac, as shown in Figure 1 (reaction 1-4). DA can be oxidized into its quinonoid form (Figure 1, reaction 1) either through a reversible electrochemical method or an irreversible chemical method under the catalysis of Lac, which can be described simply as follows [7]:

$$
\begin{aligned}
& o, m, p \text { - benzenediol }+1 / 2 \quad \mathrm{O}_{2} \stackrel{\text { laccase }}{\longrightarrow} o, m, p \\
& \quad-\text { quinone }+\mathrm{H}_{2} \mathrm{O} \\
& o, m, p-\text { quinone }+\mathrm{H}^{+}+2 \mathrm{e}^{-} \\
& \quad \rightarrow o, m, p \text { - benzenediol }
\end{aligned}
$$

The quinones formed in reaction (1) are usually electrochemically active and subsequently re-reduced on the surface of the electrode at the appropriate potentials. DA, as a typical model of $o$-benzenediol, follows this reaction mechanism. Then, Lac is used to initialize the sequential intramolecular cyclization reactions of DA, including a deprotonation reaction (Figure 1, reaction 2), an intramolecular cyclization process (reaction 3), and a disproportionation reaction and/or oxidation (reaction 4). The finally formed 5,6-dihydroxyindoline quinone is readily electrochemically reduced at SPE [32]. On the
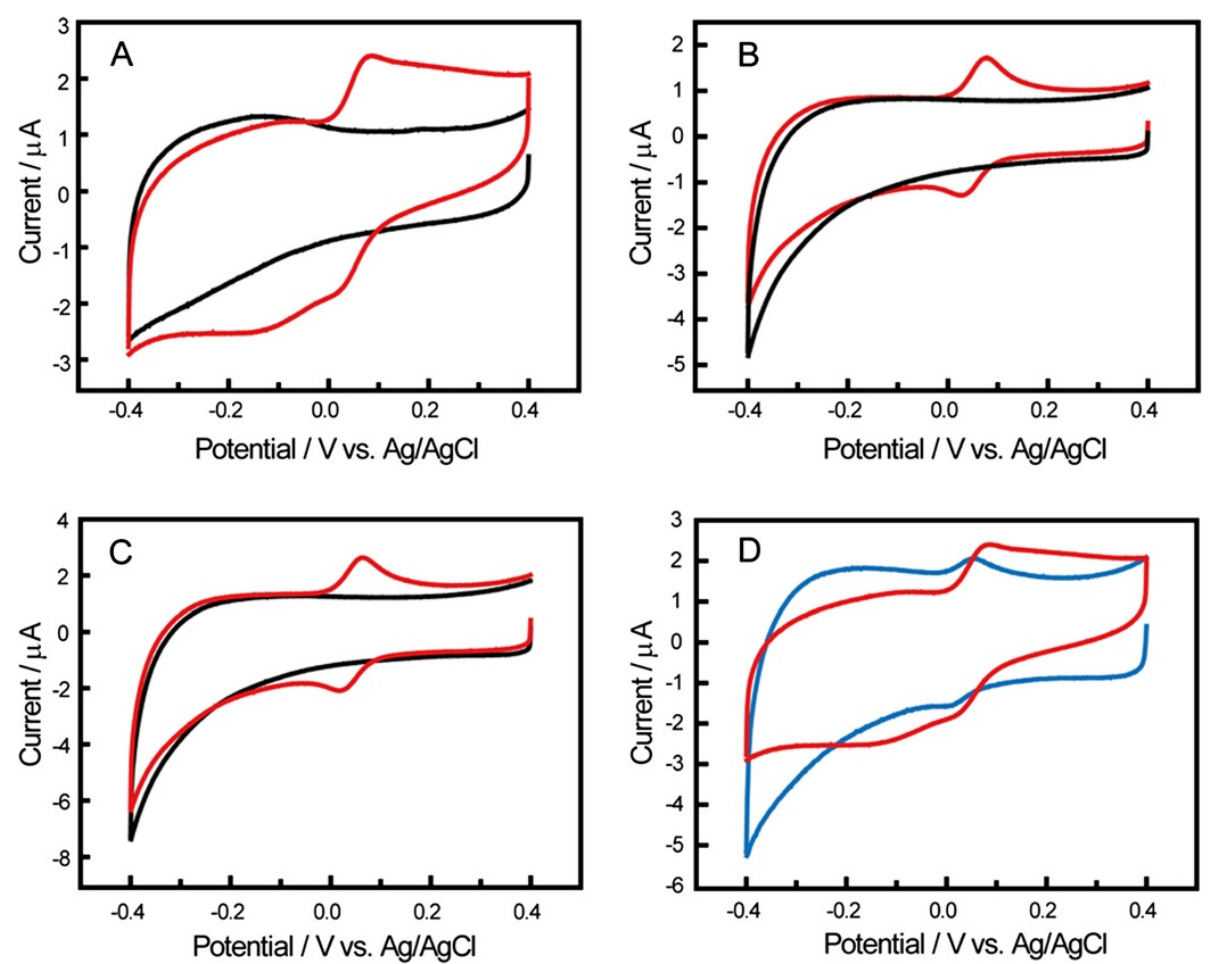

Figure $3 \mathrm{CVs}$ of Lac/Si/MWCNTs/SPE (A), Lac/SPE (B), Lac/MWCNTs/SPE (C) in $0.10 \mathrm{M}$ PBS (pH 5.0) in the absence (black curves) and presence of $60 \mu \mathrm{M}$ DA (red curves). (D) CVs of Si/MWCNTs/SPE (blue curve) and Lac/Si/MWCNTs/SPE (red curve) in $0.10 \mathrm{M} \mathrm{PBS} \mathrm{(pH} \mathrm{5.0)} \mathrm{in} \mathrm{the}$ presence of $60 \mu \mathrm{M}$ DA. Scan rate: $50 \mathrm{mV} \mathrm{s}^{-1}$. 
basis of these reaction properties of DA, the nonoxidative electrochemical approach can be proposed for the determination of DA by measuring the cathodic current of 5,6-dihydroxyindoline quinone at a negative potential $(-0.158 \mathrm{~V})$.

The results of Figure $3 \mathrm{~B}$ and $\mathrm{C}$ show that symmetrical redox couple of DA at the Lac/SPE and the Lac/ MWCNTs/SPE with the potential difference between anodic and cathodic peaks $\left(\Delta \mathrm{E}_{\mathrm{p}}\right)$ are $0.051 \mathrm{~V}$ and $0.044 \mathrm{~V}$, characteristic of a two-electron and twoproton quasi-reversible redox process of DA at both SPEs [32]. No cathodic peak at around $-0.150 \mathrm{~V}$ is found at these SPEs. The results demonstrate that the $\mathrm{Lac} / \mathrm{SPE}$ or the Lac/MWCNTs/SPE does not have any appreciable electrocatalytic activity to DA based on a non-oxidative electrochemical approach, implying the direct immobilization of Lac on bare SPE or MWCNTs/SPE is not successful. Moreover, the electrocatalytic features of the Si/MWCNTs/SPE to DA are similar to those of the Lac/SPE and the Lac/MWCNTs/ SPE in terms of the anodic $(0.057 \mathrm{~V})$ and cathodic $(0.015 \mathrm{~V})$ peak potentials (blue curve in Figure 3D), and there is still no cathodic peak at around $-0.150 \mathrm{~V}$ appearing at this Si/MWCNTs/SPE. However, after immobilizing Lac on the surface of the MWCNTs/SPE with silica spheres, the cathodic peak caused by the enzymatic oxidation of DA appears at around $-0.158 \mathrm{~V}$ (red curve in Figure 3D). Obviously, this process is ascribed to the two-electron and two-proton quasireversible redox process of 5,6-dihydroxyindoline quinone, and implies that the Lac has been immobilized on the Lac/Si/MWCNTs/SPE stably with a good biocatalytic activity [2]. Furthermore, the introduction of Lac makes the measurement of DA through cathodic current at negative potential (around $-0.150 \mathrm{~V}$ ) achieve, which avoiding the interference of other electroactive species whose oxidized potentials are very close to DA, by measuring the oxidation current of DA at a positive potential. These phenomena substantially demonstrate that the disposable biosensor can show an excellent electrocatalytic activity to DA based on this non-oxidative electrochemical approach. On one hand, the biosensor could retain the bioactivity of Lac to a large extent by immobilization of Lac with silica spheres on the MWCNTs/SPE. On the other hand, silica spheres and MWCNTs can both provide large loading area for Lac by their high specific surface area. The above results also imply that the Lac immobilized on the surface of $\mathrm{Si} / \mathrm{MWCNTs} / \mathrm{SPE}$ might provoke the drastic conformation change of Lac which is in favor of the active sites of enzyme approaching the SPE. However, if cross-linking reagents were used to immobilize Lac, this maybe promotes a high degree of reticulation with Lac that blocks the process [2].
The effect of $\mathrm{pH}$ on the electrochemical properties of the disposable biosensor

Since the proton participates in the electrochemical reaction, the $\mathrm{pH}$ value of the supporting electrolyte is considered to be an important parameter affecting the electrochemical behavior of the biosensor [28]. The current responses to DA of the disposable biosensor in the $\mathrm{pH}$ range from 4.0 to 7.0 were evaluated. The results are shown in Figure 4, where the cathodic currents of DA at the Lac/Si/MWCNTs/SPE are expressed as the percentage of the maximum response obtained at an appropriate $\mathrm{pH}$. It is shown that the optimum response is obtained at about $\mathrm{pH} 5.0$, just below the neutral $\mathrm{pH}$, which is consistent with the reported work [7]. It is noteworthy that although the soluble Lac has an optimum $\mathrm{pH}$ value at around 3.0-4.0 to retain its bioactivity [33], the Lac immobilized with silica spheres on MWCNTs/SPE makes the effective $\mathrm{pH}$ values shift to 4.0-6.0. This advantage renders the Lac/Si/MWCNTs/ SPE for broad application fields. Therefore, a $\mathrm{pH}$ value of 5.0 was selected for next experiments.

\section{The effect of the amount of MWCNTs on the} electrochemical properties of the disposable biosensor

Another important parameter affecting the responses of the target analyte at the disposable biosensor is the loading amount of MWCNTs. SPEs doped with different mass proportions of carbon paste and MWCNTs were investigated in order to choose an optimum loading amount of MWCNTs. As shown in Figure 5, with the mass proportion of MWCNTs/carbon paste (MWCNTs: carbon paste) changing from $1: 50$ to $2: 5$, the cathodic current response (expressed as the percentage of the maximum response) of DA at the Lac/Si/MWCNTs/SPE

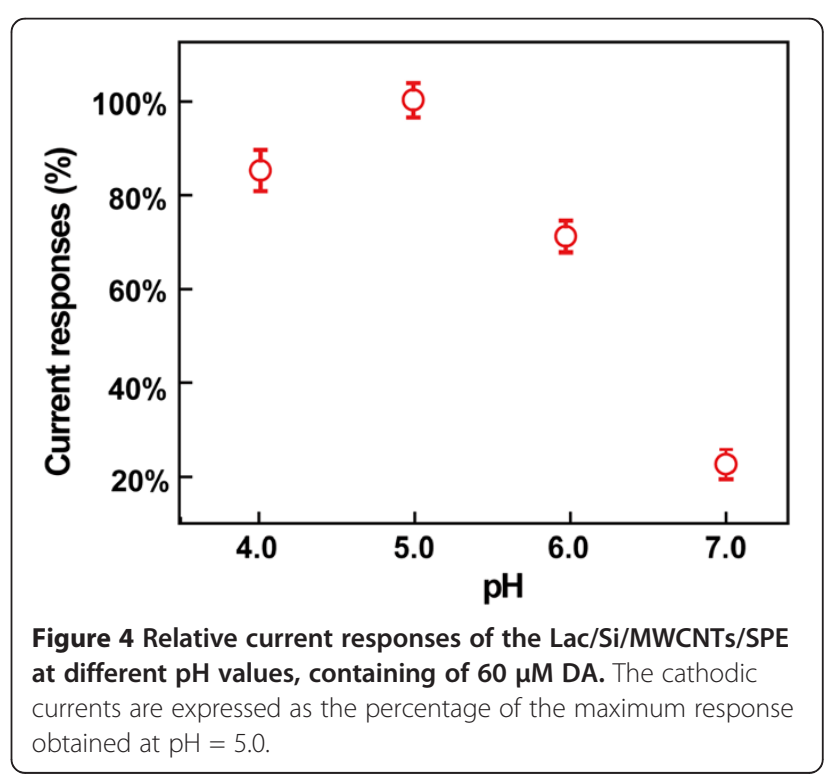




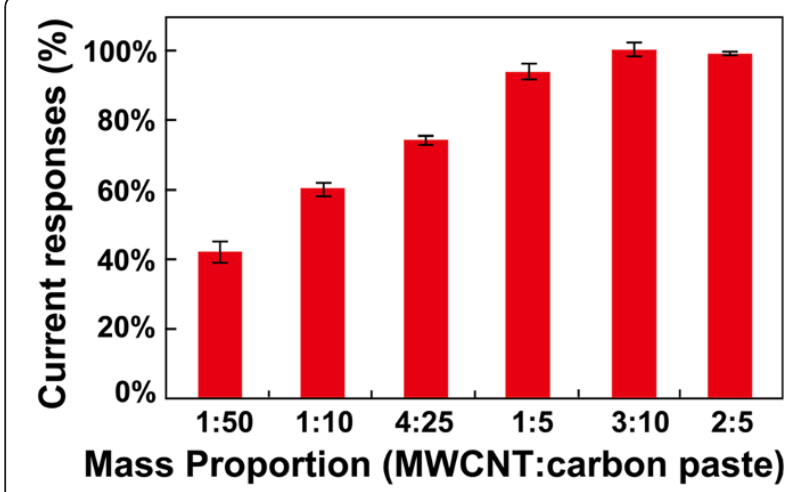

Figure 5 Relative current responses of the Lac/Si/MWCNTs/SPE loading variable amount of MWCNTs to $60 \mu \mathrm{M}$ DA in $0.10 \mathrm{M}$ PBS (pH 5.0). Scan rate: $50 \mathrm{mV} \mathrm{s}^{-1}$. The cathodic currents are expressed as the percentage of the maximum response obtained at mass proportion of MWCNTs/carbon paste of 3:10. The mass proportion of MWCNTs/carbon paste (MWCNTs:carbon paste) in the process of screen-printing is 1:50, 1:10, 4:25, 1:5, 3:10, and 2:5, respectively.

enhances, and reaching its maximum at 3:10. Therefore, the proportion of 3:10 was chosen for the fabrication of subsequent disposable Lac/Si/MWCNTs/SPEs.

\section{Determination of DA using the disposable biosensor}

The usage of Lac enables DA determination with differential pulse voltammetry (DPV), which shows a better resolution and a higher signal-to-noise ratio comparing with CV [31]. As displayed in Figure 6, the typical DPVs at the $\mathrm{Lac} / \mathrm{Si} / \mathrm{MWCNTs} / \mathrm{SPE}$ with different concentrations of DA are obtained. It can be observed that the cathodic peak current recorded at around $-0.177 \mathrm{~V}$ enhances with the increasing of the concentration of

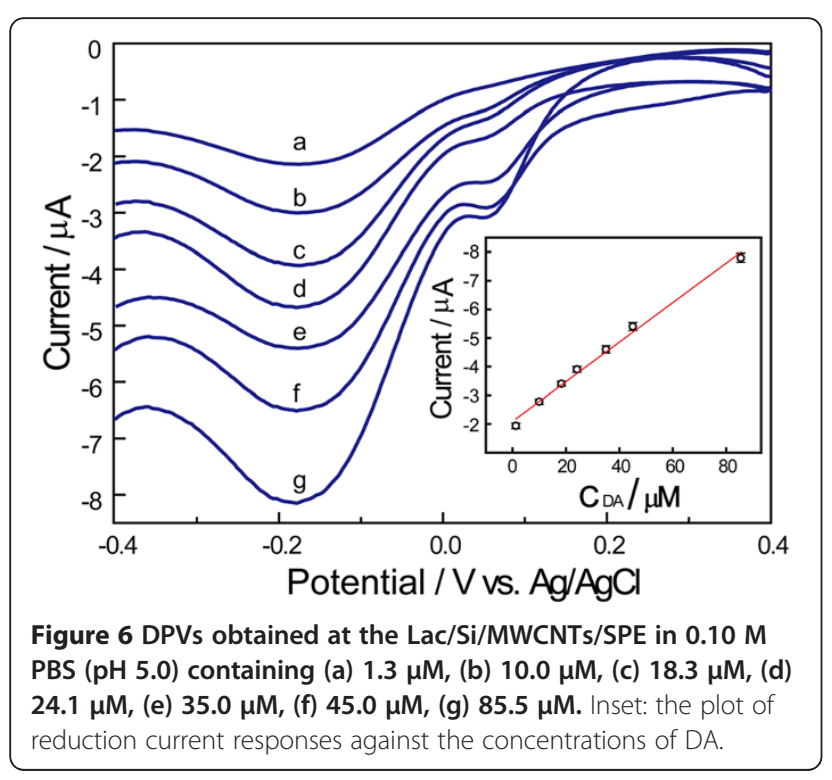

Table 1 The response properties of the disposable biosensor to DA

\begin{tabular}{llllll}
\hline $\begin{array}{l}\text { Linear } \\
\text { range } \\
(\mu \mathrm{M})\end{array}$ & $\begin{array}{l}\text { Correlation } \\
\text { coefficient }\end{array}$ & $\begin{array}{l}\text { Detection } \\
\text { limit }(\boldsymbol{\mu M})\end{array}$ & $\begin{array}{l}\text { R.S.D } \\
(\mathbf{n}=5)\end{array}$ & $\begin{array}{l}\text { Sensitivity } \\
\left(\boldsymbol{\mu} \mathbf{m M M}^{-1}\right.\end{array}$ & $\begin{array}{l}\mathrm{K}_{\mathrm{M}}^{\text {app }} \\
(\boldsymbol{\mu M})\end{array}$ \\
\hline 1.3 to 85.5 & 0.9908 & 0.42 & $4.0 \%$ & $2.787 \times 10^{3}$ & 3.78 \\
\hline
\end{tabular}

DA in solution, and the current is found to be linear with the concentration of DA from 1.3 to $85.5 \mu \mathrm{M}$ $\left(\mathrm{I}(\mu \mathrm{A})=-0.069 \mathrm{C}_{\mathrm{DA}}(\mu \mathrm{M})-2.091, \mathrm{R}=0.9908\right)$ (Inset in Figure 6). The detection limit was calculated to be $0.42 \mu \mathrm{M}(\mathrm{S} / \mathrm{N}=3)$. Furthermore, the relative standard deviation (R.S.D.), sensitivity, and Michaelis-Menten constant $\left(\mathrm{K}_{\mathrm{m}}^{\mathrm{app}}\right)$ of the disposable biosensor were evaluated (Table 1). Among them, the $\mathrm{K}_{\mathrm{m}}^{\mathrm{app}}$ value, which can provide information regarding the Lac-substrate kinetics, is calculated according to the MichaelisMenten equation [34]:

$$
I_{\max } / I_{\mathrm{s}}=K_{\mathrm{m}}{ }^{\text {app }} / \mathrm{C}+1
$$

where $I_{s}$ refers to the steady-state catalytic current, $I_{\max }$ is the maximum current measured under saturated conditions, and $\mathrm{C}$ is the concentration of DA. The $K_{\mathrm{m}}^{\mathrm{app}}$ value was estimated to be $3.78 \mu \mathrm{M}$. This small $K_{m}^{\text {app }}$ means that Lac immobilized with silica spheres on the MWCNTs/SPE possesses very high enzymatic activity for the determination of DA. These results indicate that the disposable biosensor has a good analytical performance for DA.

The selectivity of the disposable biosensor to DA determination was also investigated. AA was added into the solution which contained 85.5 $\mu \mathrm{M}$ DA (dash curves $1-3$ in Figure 7). As can be seen from Figure 7, the introduction

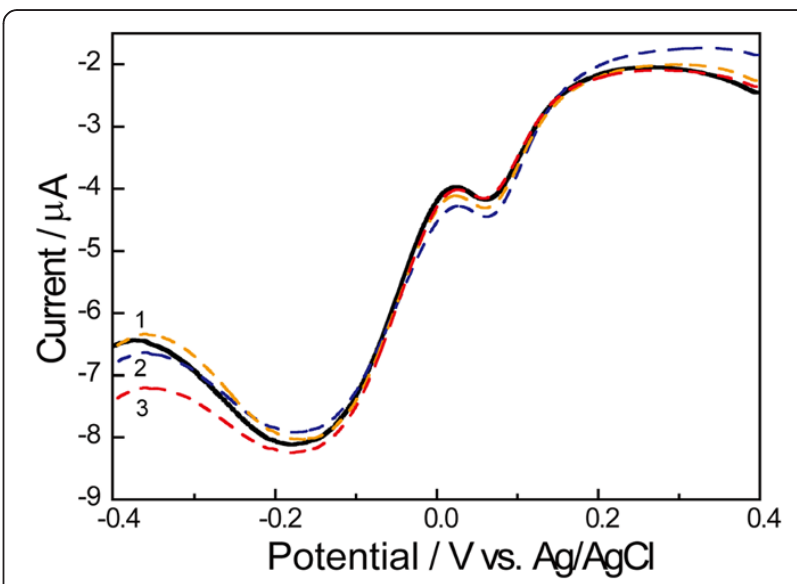

Figure 7 The selective determination of DA in the coexistence of AA. The solid curve stands for DPV obtained in $0.10 \mathrm{M} \mathrm{PBS} \mathrm{(pH}$ 5.0) containing $85.5 \mu \mathrm{M}$ DA. The dash curves 1,2 and 3 represent DPVs obtained after introducing $20.0 \mu \mathrm{M}$ (curve 1), $40.0 \mu \mathrm{M}$ (curve 2) and $60.0 \mu \mathrm{M}$ (curve 3) AA, respectively. 
of AA into DA solution does not lead to an obvious change in the cathodic peak current responses, indicating that DA can be virtually detected using $\mathrm{Lac} / \mathrm{Si} / \mathrm{MWCNTs} / \mathrm{SPE}$ due to the interference-free from AA. These results may suggest the disposable biosensor could be used for the practical measurements of DA based on the non-oxidative mechanism.

\section{Stability, reproducibility and repeatability of the disposable biosensor}

One of the most critical issues in constructing biosensor is the avoidance of enzyme immobilized on the surface of the electrode leaking into the solution. In this study, the stability of $\mathrm{Lac} / \mathrm{Si} / \mathrm{MWCNTs} / \mathrm{SPE}$ was investigated by recording cathodic peak current responses of the Lac/Si/MWCNTs/ SPE at different sweep segments in 0.10 M PBS (pH 5.0) containing of $60.0 \mu \mathrm{M}$ DA. It was found that the current responses stayed at the same level after 20 sweep segments, indicating that Lac was immobilized stably on the SPE. The results further proved that the proposed immobilization method was effective and it was not necessary to use any other cross-linking reagents. The possible reason may be due to the large loading area, good biocompatibility and the stabilizing property provided by silica spheres and MWCNTs, attributing to their porous and threedimensional architecture. The nanosized pores on silica spheres and MWCNTs could act as small cages surrounding the Lac, consequently offering a protective chemical microenvironment which is similar to the microenvironment near enzyme in biological cells. Furthermore, the interconnected pores and a well-defined three-dimensional network of the proposed immobilization matrix can prevent Lac from leaching into the solution while allow free diffusion between the matrix and product molecules from/ to the catalytic active sites. Therefore, even if in the absence of cross-linking reagents, the developed biosensor can still show good stability during the detection $[35,36]$.

To verify the reproducibility of the disposable biosensor, five different Lac/Si/MWCNTs/SPEs fabricated by same steps independently were chosen randomly from 50 pieces of store SPEs. The R.S.D. for the cathodic peak current responses to $60.0 \mu \mathrm{M}$ DA was $6.5 \%$, meaning that the constructing procedures were reliable and the modified SPEs had a good reproducibility. In addition, the same Lac/Si/MWCNTs/SPE was used to detect DA for five times successively. As a result, the R.S.D. value was $4.7 \%$, showing a good repeatability.

The storage stability of the disposable biosensor was also investigated. After 10 and 30 days saving at $4^{\circ} \mathrm{C}$, the current response of $\mathrm{Lac} / \mathrm{Si} / \mathrm{MWCNTs} / \mathrm{SPE}$ reached to $91.0 \%$ and $86.0 \%$ of the initial response respectively in the $60.0 \mu \mathrm{M}$ DA solution. The good stability may ascribe to the effective protection of the bioactivity of Lac due to the consistent stability of silica spheres and the biocompatible microenvironment provided by silica spheres and MWCNTs.

\section{Conclusions}

A novel disposable biosensor has been successfully constructed on MWCNTs/SPE by immobilizing Lac with silica spheres. Due to the large specific surface area and excellent biocompatibility of MWCNTs and silica spheres, the biosensor can effectively provide a suitable microenvironment for the immobilization of Lac and exhibit a good electrocatalytic performance for DA. In addition, based on a non-oxidative electrochemical mechanism, the biosensor enables the in situ determination of DA with good sensitivity, selectivity and reproducibility. In summary, the proposed approach of enzyme immobilization shows a great potential for the construction of biosensors without using cross-linking reagents, and the constructed biosensor displays an excellent analytical performance for phenolic compounds in a rapid and cost-effective way.

\section{Competing interests}

The authors declare that they have no competing interests.

\section{Authors' contributions}

$Y L$ carried out the experimental work, participated in data collection and analysis, involved in drafting and revising the manuscript. ML participated in fabricating SPEs and data analysis. LZ, DL, ZP revised it critically for important intellectual content, and gave final approval of the version to be published. All authors read and approved the final manuscript.

\section{Acknowledgements}

This research was supported by the National Science Fund for Distinguished Young Scholars (No. 21125522) and Natural Science Foundation of China (Grant No. 21007015).

Received: 18 July 2012 Accepted: 3 September 2012

Published: 17 September 2012

\section{References}

1. Tan YM, Deng WF, Ge B, Xie QJ, Huang JH, Yao SZ: Biofuel cell and phenolic biosensor based on acid-resistant laccase-glutaraldehyde functionalized chitosan-multiwalled carbon nanotubes nanocomposite film. Biosens Bioelectron 2009, 24:2225-2231.

2. Liu Y, Qu XH, Guo HW, Chen HJ, Liu BF, Dong SJ: Facile preparation of amperometric laccase biosensor with multifunction based on the matrix of carbon nanotubes-chitosan composite. Biosens Bioelectron 2006, 21:2195-2201.

3. Zhou M, Dong SJ: Bioelectrochemical Interface Engineering: Toward the fabrication of electrochemical biosensors, biofuel cells, and self-powered logic biosensors. Acc Chem Res 2011, 44:1232-1243.

4. Le Goff A, Holzinger M, Cosnier S: Enzymatic biosensors based on SWCNTconducting polymer electrodes. Analyst 2011, 136:1279-1287.

5. Zhang L, Yuan FF, Zhang XH, Yang LM: Facile synthesis of flower like copper oxide and their application to hydrogen peroxide and nitrite sensing. Chem Central J 2011, 5:75-83.

6. Shin CLY, Liu J, Ackerman EJ: Entrapping enzyme in a functionalized nanoporous support. J Am Chem Soc 2002, 124:11242-11243.

7. Shimomura T, Itoh T, Sumiya T, Hanaoka T, Mizukami F, Ono M: Amperometric detection of phenolic compounds with enzyme immobilized in mesoporous silica prepared by electrophoretic deposition. Sens Actuators B 2011, 153:361-368.

8. Salis A, Pisano M, Monduzzi M, Solinas V, Sanjust E: Laccase from Pleurotus sajor-caju on functionalised SBA-15 mesoporous silica: immobilisation 
and use for the oxidation of phenolic compounds. J Mol Catal B: Enzym 2009, 58:175-180.

9. Zawisza I, Rogalski J, Opallo M: Electrocatalytic reduction of dioxygen by redox mediator and laccase immobilised in silicate thin film. J Electroanal Chem 2006, 588:244-252

10. Zhu YF, Kaskel S, Shi JL, Wage T, Pee KH: Immobilization of Trametes versicolor laccase on magnetically separable mesoporous silica spheres. Chem Mater 2007, 19:6408-6413.

11. Wang J: Carbon-nanotube based electrochemical biosensors: a review. Electroanal 2005, 17:7-14

12. Shah S, Solanki K, Gupta MN: Enhancement of lipase activity in nonaqueous media upon immobilization on multi-walled carbon nanotubes. Chem Central J 2007, 1:30-35.

13. Luong JHT, Hrapovic S, Wang D, Bensebaa F, Simard B: Solubilization of multiwall carbon nanotubes by 3-Aminopropyltriethoxysilane towards the fabrication of electrochemical biosensors with promoted electron transfer. Electroanal 2004, 16:132-139.

14. Tortolini C, Di Fusco M, Frasconi M, Favero G, Mazzei F: Laccasepolyazetidine prepolymer-MWCNT integrated system: biochemical properties and application to analytical determinations in real samples. Microchem J 2010, 96:301-307.

15. Chawla S, Rawal R, Pundir CS: Fabrication of polyphenol biosensor based on laccase immobilized on copper nanoparticles/chitosan/multiwalled carbon nanotubes/polyaniline-modified gold electrode. J Biotechnol 2011, 156:39-45.

16. Pang Y, Zeng GM, Tang L, Zhang Y, Li Z, Chen LJ: Laccase biosensor using magnetic multiwalled carbon nanotubes and chitosan/silica hybrid membrane modified magnetic carbon paste electrode. J Cent South Univ Technol 2011, 18:1849-1856.

17. Opallo M, Bilewicz R: Recent developments of nanostructured electrodes for bioelectrocatalysis of dioxygen reduction. Adv Phys Chem 2011, 2011:1-21.

18. Rawal R, Chawla S, Pundir CS: Polyphenol biosensor based on laccase immobilized onto silver nanoparticles/multiwalled carbon nanotube/ polyaniline gold electrode. Anal Biochem 2011, 419:196-204.

19. Renedo OD, González MJG, Arcos-Martínez MJ: Determination of antimony (III) in real samples by anodic stripping voltammetry using a mercury film screen-printed electrode. Sensors 2009, 9:219-231.

20. Tortolini C, Fusco MD, Frasconi M, Favero G, Mazzei F: Laccasepolyazetidine prepolymer-MWCNT integrated system: Biochemical properties and application to analytical determinations in real samples. Microchem J 2010, 96:301-307.

21. Montereali MR, Della Seta L, Vastarella W, Pilloton R: A disposable laccasetyrosinase based biosensor for amperometric detection of phenolic compounds in must and wine. J Mol Catal B: Enzym 2010, 64:189-194.

22. Ibarra-Escutia P, Gomez JJ, Calas-Blanchard C, Marty JL, Ramirez-Silva MT: Amperometric biosensor based on a high resolution photopolymer deposited onto a screen-printed electrode for phenolic compounds monitoring in tea infusions. Talanta 2010, 81:1636-1642.

23. Martínez-Paredes G, González-García MB, Costa-García A: In situ electrochemical generation of gold nanostructured screen-printed carbon electrodes. Application to the detection of lead underpotential deposition. Electrochim Acta 2009, 54:4801-4808

24. Sánchez A, Morante-Zarcero S, Pérez-Quintanilla D, Sierra I, Hierro I: Development of screen-printed carbon electrodes modified with functionalized mesoporous silica nanoparticles: Application to voltammetric stripping determination of $\mathrm{Pb}(\mathrm{II})$ in non-pretreated natural waters. Electrochim Acta 2010, 55:6983-6990.

25. Ren R, Leng CC, Zhang SS: A chronocoulometric DNA sensor based on screen-printed electrode doped with ionic liquid and polyaniline nanotubes. Biosens Bioelectron 2010, 25:2089-2094.

26. Wang J, Chen L: Hydrazine detection using a tyrosinase-based inhibition biosensor. Anal Chem 1995, 67:3824-3827.

27. Lisdat F, Ho WO, Wollenberger U, Scheller FW, Richter T, Bilitewski U: Recycling systems based on screen-printed electrodes. Electroanal 1998, 10:803-807.

28. Li DW, Li YT, Song W, Long YT: Simultaneous determination of dihydroxybenzene isomers using disposable screen-printed electrode modified by multiwalled carbon nanotubes and gold nanoparticles. Anal Methods 2010, 2:837-843.
29. Song W, Li DW, Li YT, Li Y, Long YT: Disposable biosensor based on graphene oxide conjugated with tyrosinase assembled gold nanoparticles. Biosens Bioelectron 2011, 26:3181-3186.

30. Stöber W, Fink A, Bohn E: Controlled growth of monodisperse silica spheres in the micron size range. J Colloid Interface Sci 968, 26:62-69.

31. Xiang L, Lin YQ, Yu P, Su L, Mao LQ: Laccase-catalyzed oxidation and intramolecular cyclization of dopamine: A new method for selective determination of dopamine with laccase/carbon nanotube-based electrochemical biosensors. Electrochim Acta 2007, 52:4144-4152.

32. Lin YQ, Zhang ZP, Zhao LZ, Wang X, Yu P, Su L, Mao LQ: A non-oxidative electrochemical approach to online measurements of dopamine release through laccase-catalyzed oxidation and intramolecular cyclization of dopamine. Biosens Bioelectron 2010, 25:1350-1355.

33. Roy JJ, Abraham TE, Abhijith KS, Sujith Kumar PV, Thakur MS: Biosensor for the determination of phenols based on Cross-Linked Enzyme Crystals (CLEC) of laccase. Biosens Bioelectron 2005, 21:206-211.

34. Shu FR, Wilson GS: Rotating ring-disk enzyme electrode for surface catalysis studies. Anal Chem 1976, 48:1679-1686.

35. Wang J, Lin YH: Functionalized carbon nanotubes and nanofibers for biosensing applications. Trends Anal Chem 2008, 27:619-626.

36. Ispas C, Sokolov I, Andreescu S: Enzyme-functionalized mesoporous silica for bioanalytical applications. Anal Bioanal Chem 2009, 393:543-554.

doi:10.1186/1752-153X-6-103

Cite this article as: Li et al: A disposable biosensor based on

immobilization of laccase with silica spheres on the MWCNTs-doped screen-printed electrode. Chemistry Central Journal 2012 6:103.

Publish with ChemistryCentral and every
scientist can read your work free of charge
"Open access provides opportunities to our
colleagues in other parts of the globe, by allowing
anyone to view the content free of charge."
W. Jeffery Hurst, The Hershey Company.
- available free of charge to the entire scientific community
- peer reviewed and published immediately upon acceptance
- cited in PubMed and archived on PubMed Central
- yours - you keep the copyright
submit your manuscript here:
http://www.chemistrycentral.com/manuscript/

